\title{
Recurrent Laryngeal Verrucous
}

\section{Carcinoma}

National Cancer Institute

\section{Source}

National Cancer Institute. Recurrent Laryngeal Verrucous Carcinoma. NCI Thesaurus.

Code C8246.

The reemergence of verrucous carcinoma of the larynx after a period of remission. 